\title{
EGFR NP_005219.2:p.K745_A750del
}

National Cancer Institute

\section{Source}

National Cancer Institute. EGFR NP 005219.2:p.K745 A750del. NCI Thesaurus. Code C98534.

A deletion of six amino acids from the epidermal growth factor receptor protein from the lysine at position 745 through the alanine at position 750 . 